\title{
Solid Particle Erosion of Date Palm Leaf Fiber Reinforced Polyvinyl Alcohol Composites
}

\author{
Jyoti R. Mohanty, ${ }^{1}$ Sankar N. Das, ${ }^{2}$ Harish C. Das, ${ }^{2}$ \\ Tapan K. Mahanta, ${ }^{3}$ and Sataya B. Ghadei ${ }^{4}$ \\ ${ }^{1}$ Department of Mechanical Engineering, Veer Surendra Sai University of Technology, Burla, Sambalpur 768018, India \\ ${ }^{2}$ Department of Mechanical Engineering, SOA University, Bhubaneswar 751030, India \\ ${ }^{3}$ Department of Mechanical Engineering, IIT Hyderabad, Andhra Pradesh 502205, India \\ ${ }^{4}$ Mahindra \& Mahindra Ltd., Tamil Nadu 603204, India
}

Correspondence should be addressed to Jyoti R. Mohanty; guddy95@gmail.com

Received 2 October 2013; Accepted 8 December 2013; Published 22 January 2014

Academic Editor: Patrick De Baets

Copyright (C) 2014 Jyoti R. Mohanty et al. This is an open access article distributed under the Creative Commons Attribution License, which permits unrestricted use, distribution, and reproduction in any medium, provided the original work is properly cited.

Solid particle erosion behavior of short date palm leaf (DPL) fiber reinforced polyvinyl alcohol (PVA) composite has been studied using silica sand particles $(200 \pm 50 \mu \mathrm{m})$ as an erodent at different impingement angles $\left(15-90^{\circ}\right)$ and impact velocities $(48-109 \mathrm{~m} / \mathrm{s})$. The influence of fiber content ( $\mathrm{wt} \%$ of DPL fiber) on erosion rate of PVA/DPL composite has also been investigated. The neat PVA shows maximum erosion rate at $30^{\circ}$ impingement angle whereas PVA/DPL composites exhibit maximum erosion rate at $45^{\circ}$ impingement angle irrespective of fiber loading showing semiductile behavior. The erosion efficiency of PVA and its composites varies from 0.735 to $16.289 \%$ for different impact velocities studied. The eroded surfaces were observed under scanning electron microscope (SEM) to understand the erosion mechanism.

\section{Introduction}

Material scientists are constantly searching for new nonconventional materials to replace the conventional metallic materials. With this effort the development of fiber reinforced polymer (FRP) composite, reinforced with both synthetic and natural fibers, finds its place for applications ranging from household appliances to advanced space and defense equipment due to its excellent specific properties. Environmental awareness has triggered the researchers worldwide to replace traditional synthetic fibers with natural fibers because of certain advantages such as low price, low density, unlimited and sustainable availability, and low abrasive wear of processing machinery $[1,2]$. However, they have certain disadvantages like high moisture absorption, poor wettability, low mechanical properties, and so forth. In spite of these disadvantages, the interest in natural fiber polymer composites is rapidly growing in terms of their tribological and industrial applications [3].
With regard to tribological application, natural fiber polymer composites encounter different types of wears in practical situations. Solid particle erosion is one of the typical wear modes which is characterized by the loss of materials that results from repeated impact of small solid particles. It occurs in various situations like pipe line carrying sand slurries in petroleum refining, helicopter rotor blades, pump impeller blades, high speed vehicles, and aircraft operating in desert environments, radomes, surfing boats, and so forth. In those situations the components come across impact of lot of abrasives like dust, sand, splinters of materials, slurry of solid particles, and so forth, and consequently the material undergoes erosive wear [4]. Till date, most of the research works have been devoted to study the solid particle erosion behavior of synthetic polymers reinforced in either thermoset or thermoplastic polymer matrices [5-8]. The works towards the study of erosive wear of natural fiber reinforced polymer composites are scanty in the literature. Recently, Patel et al. [9] have investigated the erosive wear behavior of jute-glass 
fabric reinforced epoxy composite and concluded that the erosion property of jute/epoxy composite can be improved significantly by hybridizing with synthetic fiber glass. Biswas and Satapathy [10] have observed that the erosion wear performance of red mud filled bamboo-epoxy composites is better than that of glass-epoxy composites. In another work Satapathy et al. [11] have studied the erosion of fish scale reinforced epoxy composite and found that its erosion performance is better than that of neat epoxy. In general it is seen that the erosion resistance of polymer composites is poorer than that of neat polymers [12-14]. However, reinforcement may improve or worsen the resistance to erosion, depending on the types of fibers used [15].

The date palm tree, a member of the palm tree family (Phoenix dactylifera), is normally found in the Middle East, Northern Africa, the Canary Islands, Pakistan, India, and the United States (California). As per the reported work [16] there are approximately 62 million of date palm trees found in the Middle East and North Africa and 100 million worldwide. In Saudi Arabia alone, 15000 tons of date palm leaves is produced as waste. The leaves of date palm tree are used in making ropes, baskets, and mats in many parts of the world. However, the bulk of the material is discarded as waste. Therefore, efficient utilization of this natural resource in making natural fiber composite would have a positive impact on environment and may improve the economic standard of rural people. In this context, some works [17-20] have been undertaken to study various properties of date palm leaf fiber reinforced polymer composites. It has also been reported that the specific strength of date palm leaf is higher than many aluminium alloys [21]. With this background, it was worthwhile to understand the erosive wear behavior of date palm leaf reinforced polymer composite. Authors in their earlier work [22] have studied the mechanical properties of acrylic acid treated date palm leaf fiber reinforced polyvinyl alcohol (PVA/DPL) composites and observed that $28 w \mathrm{t} \%$ of DPL fiber gives optimum mechanical properties. In the present investigation, erosion test was conducted on PVA/DPL composites at various fiber loadings such as 10 , 20,30 , and $40 \mathrm{wt} \%$ including optimum fiber loading (i.e., $28 \mathrm{wt} \%$ ) in order to study solid particle erosion behavior of the composite for tribological applications.

\section{Experimental}

2.1. Fabrication of Composite Specimen. The date palm leaf (DPL) fibers were prepared by tearing out the strips of date palm leaves with $1.5 \mathrm{~cm}$ long and $1 \mathrm{~mm}$ wide and given surface modification with acrylic acid. Composite specimens were fabricated by mixing different weight percentages (i.e., 10, 20, 28,30 , and $40 \mathrm{wt} \%$ ) of acrylic acid modified DPL fiber with polyvinyl alcohol (PVA) matrix by injection molding method for solid particle erosion test.

2.2. Erosion Wear Test. The solid particle erosion experiments were carried out as per ASTM G76 standard on the erosion test rig shown in Figure 1. The rig consists of an air compressor, a particle feeder, an air particle mixing, and accelerating chamber. The dried and compressed air were
TABLE 1: Erosion test conditions.

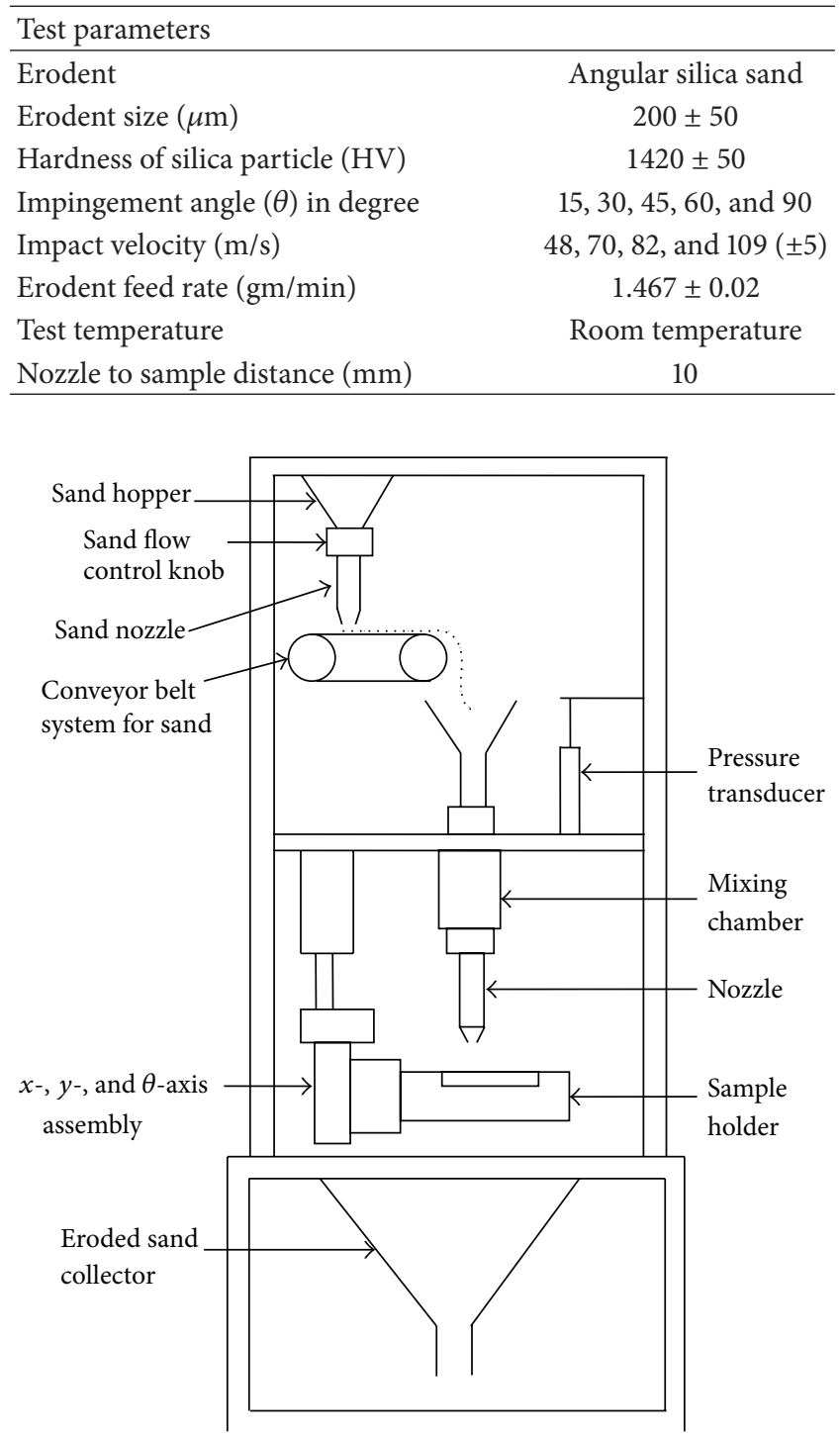

FIGURE 1: Schematic diagram of erosion test rig.

mixed with silica sand $(200 \pm 50 \mu \mathrm{m})$ which was fed constantly from a conveyor belt feeder into the mixing chamber. The silica particles were accelerated by passing through a tungsten carbide converging nozzle of $4 \mathrm{~mm}$ diameter to bombard the target. The composite specimens were held at selected angles $\left(15^{\circ}, 30^{\circ}, 45^{\circ}, 60^{\circ}\right.$, and $\left.90^{\circ}\right)$ with respect to the flow of the impacting sand particles and eroded.

The feed rate of the particles was controlled by monitoring the distance between the particle feeding hopper and belt drive carrying the particles to mixing chamber. The impact velocity of the particles was varied by varying the pressure of the compressed air. The velocity of the eroding particles was determined using a rotating disc method [23]. The conditions under which erosion tests were carried out are listed in Table 1.

The samples were cleaned in acetone, dried, and weighed to the accuracy of $0.1 \mathrm{mg}$ using an electronic balance, before 

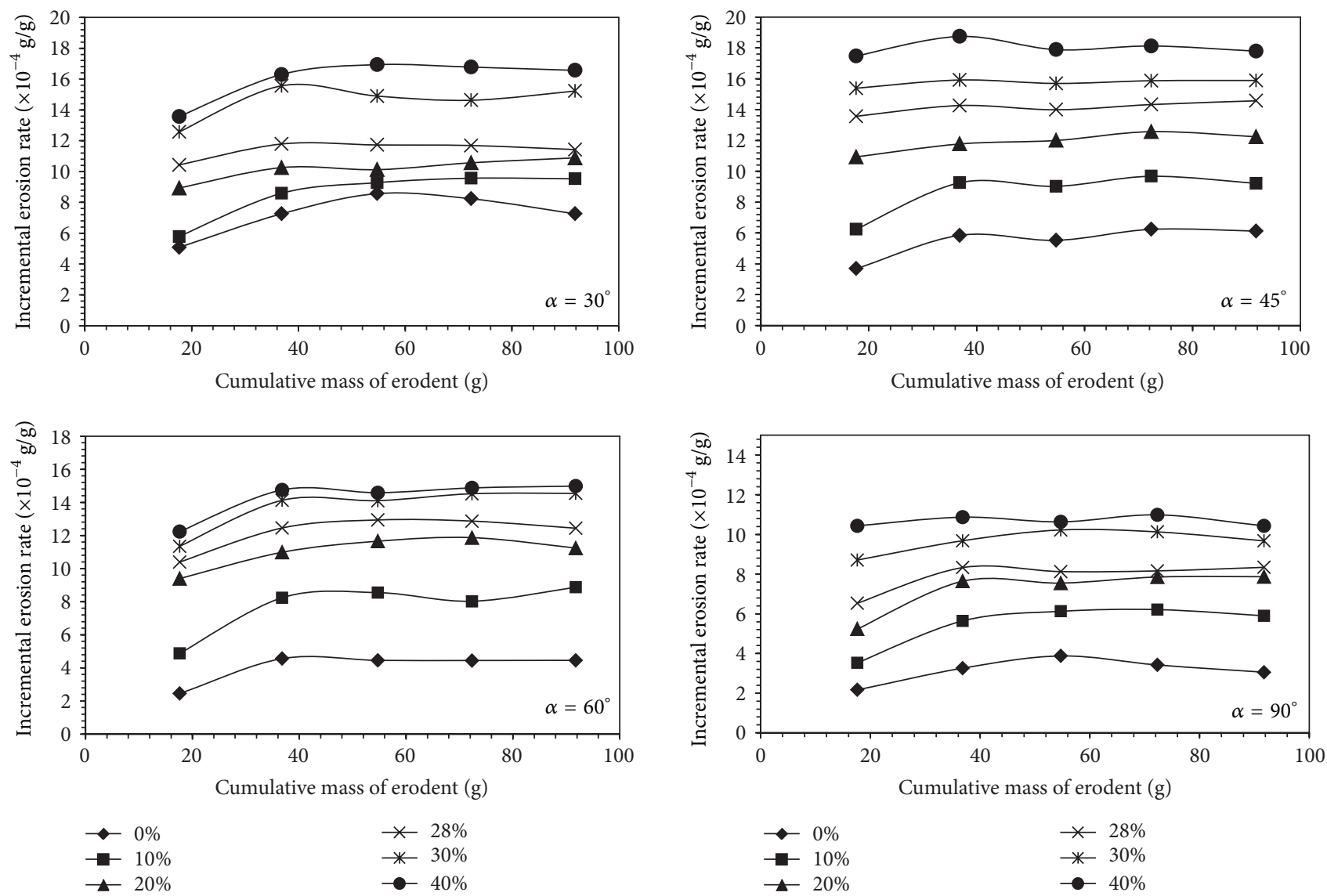

FIGURE 2: Variation of erosion rate of PVA/DPL composites as a function of cumulative weight of impinging particle at different impingement angles $\left(15-90^{\circ}\right)$.

and after each test. The test samples after loading in the test rig were eroded for 3 min at a given impingement angle and then weighed again to determine weight loss $(\Delta w)$. The erosion rate $(E)$ is then calculated by using the following equation:

$$
E=\frac{\Delta w}{w_{e}}
$$

where $\Delta w$ is the mass loss of test sample in gm and $w_{e}$ is the mass of eroding particles (i.e., testing time $\times$ particle feed rate). This procedure has been repeated until the erosion rate attains a constant steady-state value. In the present study the same procedure is repeated for 5 times (i.e., expose time was $15 \mathrm{~min})$.

2.3. Characterization of Eroded Surfaces. The characterization of eroded surfaces was done using JOEL (JSM 840) scanning electron microscope (SEM). Before taking the SEM image, the samples were gold sputtered in order to reduce charging of the surface.

\section{Results and Discussions}

3.1. Influence of Cumulative Weight of the Impinging Particle on Erosion Rate. The typical variation of incremental erosion rate as a function of cumulative mass of erodent for various weight percentages of PVA/DPL composites is shown in Figure 2. The erosion data pertaining to different impact angles at impact velocity of $70 \mathrm{~m} / \mathrm{s}$ has been presented. As depicted from the graphs, no incubation or induction period is observed. However, acceleration, deceleration, and stabilization are exhibited by different weight percentages of PVA/DPL composites. A similar kind of observations was also reported in the literature [24] while studying erosive wear behavior of polyetherimide and its composites. It can also be seen from Figure 2 that erosion rates of PVA and its composites reach nearer to steady-state value when the cumulative mass of erodent is in the range of about 40-70 g. Further, it is observed that steady-state erosion rate of PVA and its composites increases with increase in impingement angles from $15^{\circ}$ to $45^{\circ}$, then it decreases at higher impact angles (i.e., $60^{\circ}$ and $90^{\circ}$ ). The similar observations were made for the other impact velocities and hence it is not shown here.

3.2. Influence of Impingement Angle ( $\alpha$ ) on Erosion Rate. The material removal during the erosion is dependent on many interrelated factors that include the properties and structure of target material, exposure conditions, and physical, chemical characteristics of the erodent particles. Hence, erosive wear of polymers/composites is a more complex process 

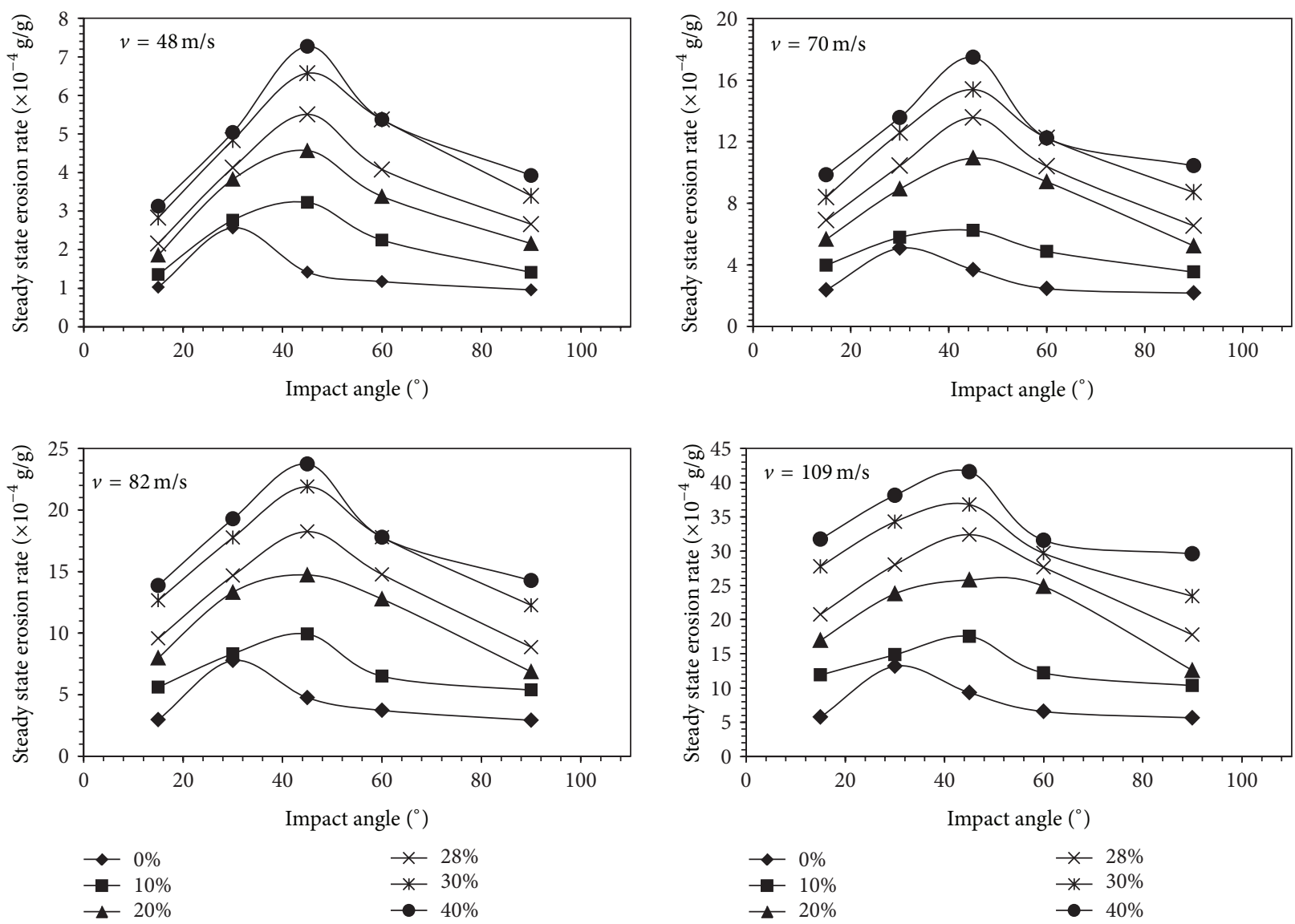

FIGURE 3: Influence of impingement angle $(\alpha)$ on steady-state erosion rate of PVA/DPL composite.

and no single property/mechanism can completely account for the loss of material [24]. It is known that impingement angle is one of the most important parameters as the erosion behaviour of materials can be broadly classified as ductile and brittle depending on the variation of the erosion rate with impingement angle [25]. Ductile behavior is characterized by maximum erosion rate at low impingement angle, typically between $15^{\circ}$ to $30^{\circ}$. On the other hand, if the maximum erosion rate occurs at normal impact (i.e., at $90^{\circ}$ ), the behavior of the material is brittle. Reinforced composites have been found to exhibit semiductile behaviour with the maximum erosion rate being at intermediate angles, typically between $45^{\circ}$ to $60^{\circ}$. To study the influences of impingement angle on wear behavior of PVA/DPL composites, the steadystate erosion rate has been correlated with impingement angle for different weight percentages of DPL fibers in Figure 3.

It is evident from the figures that steady-state erosion rate is maximum at $30^{\circ}$ impingement angle for neat PVA (i.e., $0 \mathrm{wt} \%$ ) whereas other weight percentages of PVA/DPL composites show peak erosion rate at $45^{\circ}$ impingement angle at all impact velocities. Therefore, DPL fiber reinforced PVA composites exhibit semiductile behavior with maximum erosion rate at $45^{\circ}$ impingement angle.

3.3. Influence of Impact Velocity ( $v$ ) on Erosion Rate. In order to study the effect of particle velocity on erosion rate, erosion tests were conducted by varying the particle velocity from 48 to $109 \mathrm{~m} / \mathrm{s}$ for various impingement angles $\left(15-90^{\circ}\right)$. The variations of erosion rates with different fiber loadings of PVA and its composites at impact angle of $45^{\circ}$ are illustrated in the form of bar chart (Figure 4). From the chart it is found that erosion rates increase with incorporation of DPL fibers at all impact velocities. This type of trend is also observed at all other impact angles.

Figure 5 shows the typical steady-state erosion rate dependence of PVA and its composites for different impact velocities at two impingement angles $\left(45^{\circ}\right.$ and $\left.90^{\circ}\right)$. It is found that steady-state erosion rate of PVA and its composites increases with increase in impact velocity for the tested impingement angles.

It has been observed earlier [26] that the velocity of the erosive particles has a very strong effect on erosion rate and the relation between erosion rate $(E)$ and impact velocity $(v)$ can be expressed by using the power law equation:

$$
E=K v^{n}
$$

where " $E$ " is the steady-state erosion rate, " $v$ " is the impact velocity of particles, " $n$ " is the velocity exponent, and " $k$ " is a constant. The least-square fits to the data points were obtained by using the above power law (Figure 5) equation and the fitting parameters at different impingement angles are summarized in Table 2. 
TABLE 2: Parameters characterizing the velocity dependence of erosion rate of PVA/DPL composites.

\begin{tabular}{|c|c|c|c|c|}
\hline $\begin{array}{l}\text { Wt\% of } \\
\text { DPL fiber }\end{array}$ & $\begin{array}{c}\text { Impingement } \\
\text { angle }\left(\alpha,{ }^{\circ}\right)\end{array}$ & $k$ & $n$ & $R^{2}$ \\
\hline \multirow{5}{*}{0} & 15 & $1 \times 10^{-8}$ & 2.072 & 0.996 \\
\hline & 30 & $2 \times 10^{-7}$ & 2.018 & 0.995 \\
\hline & 45 & $1 \times 10^{-8}$ & 2.277 & 0.996 \\
\hline & 60 & $3 \times 10^{-8}$ & 2.118 & 0.997 \\
\hline & 90 & $1 \times 10^{-8}$ & 2.154 & 0.999 \\
\hline \multirow{5}{*}{10} & 15 & $5 \times 10^{-9}$ & 2.637 & 0.998 \\
\hline & 30 & $4 \times 10^{-7}$ & 2.56 & 0.999 \\
\hline & 45 & $3 \times 10^{-7}$ & 2.88 & 0.992 \\
\hline & 60 & $1 \times 10^{-8}$ & 2.05 & 0.999 \\
\hline & 90 & $2 \times 10^{-8}$ & 2.438 & 0.999 \\
\hline \multirow{5}{*}{20} & 15 & $6 \times 10^{-9}$ & 2.683 & 0.997 \\
\hline & 30 & $3 \times 10^{-8}$ & 2.242 & 0.998 \\
\hline & 45 & $5 \times 10^{-7}$ & 2.109 & 0.997 \\
\hline & 60 & $1 \times 10^{-8}$ & 2.422 & 0.996 \\
\hline & 90 & $2 \times 10^{-8}$ & 2.138 & 0.997 \\
\hline \multirow{5}{*}{28} & 15 & $6 \times 10^{-9}$ & 2.742 & 0.996 \\
\hline & 30 & $4 \times 10^{-8}$ & 2.332 & 0.999 \\
\hline & 45 & $5 \times 10^{-7}$ & 2.158 & 0.996 \\
\hline & 60 & $1 \times 10^{-8}$ & 2.334 & 0.998 \\
\hline & 90 & $2 \times 10^{-8}$ & 2.301 & 0.999 \\
\hline \multirow{5}{*}{30} & 15 & $6 \times 10^{-9}$ & 2.779 & 0.999 \\
\hline & 30 & $3 \times 10^{-8}$ & 2.384 & 0.999 \\
\hline & 45 & $1 \times 10^{-7}$ & 2.113 & 0.997 \\
\hline & 60 & $7 \times 10^{-7}$ & 2.140 & 0.999 \\
\hline & 90 & $1 \times 10^{-8}$ & 2.352 & 0.999 \\
\hline \multirow{5}{*}{40} & 15 & $6 \times 10^{-9}$ & 2.804 & 0.997 \\
\hline & 30 & $3 \times 10^{-8}$ & 2.464 & 0.998 \\
\hline & 45 & $2 \times 10^{-7}$ & 2.127 & 0.997 \\
\hline & 60 & $4 \times 10^{-7}$ & 2.170 & 0.999 \\
\hline & 90 & $1 \times 10^{-8}$ & 2.446 & 0.998 \\
\hline
\end{tabular}

From the presented data it is observed that the velocity exponents are in the range of 2.0-2.88 for the synthesized composites at different impingement angles. Generally, there is hardly any variation in the value of " $n$ " at different impingement angles and higher values of " $n$ " are associated with steeper impingement angles. Erosion behavior of materials is broadly classified as ductile and brittle based on impingement angle as mentioned earlier. However, the above classification is not absolute as the erosion behavior has a strong dependence on erosion conditions such as impact angle, impact velocity, and erodent properties such as shape, hardness, and size. It has been observed that the erosion behavior of polymers and their composites is also characterized by the value of the velocity exponent, " $n$ " [15]. For polymeric materials behaving in a ductile manner the value of " $n$ " is in the range of 2-3 while for polymer composites behaving in a brittle fashion the range is $3-5$. In the present study, since

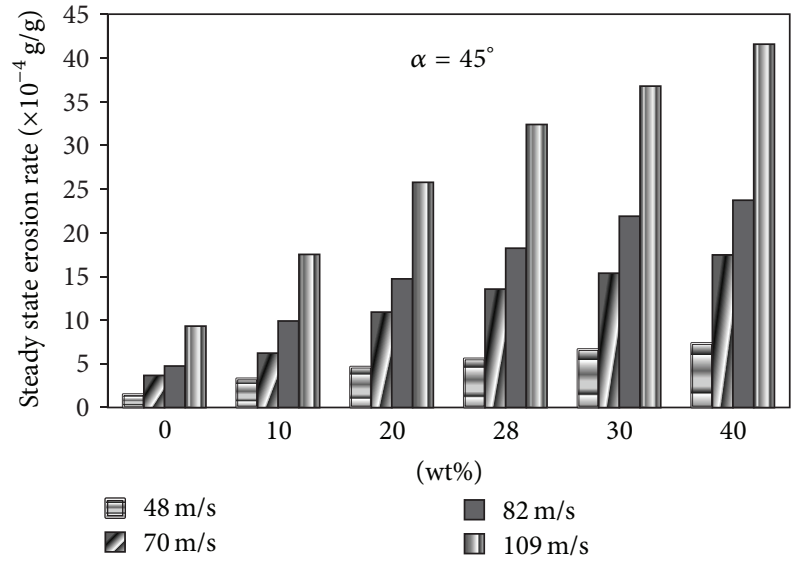

FIGURE 4: Variations of erosion rates of PVA/DPL composites with different fiber loadings.

the velocity exponents are in the range of $2.0-2.88$, hence the PVA/DPL composites exhibit semiductile behavior.

3.4. Influence of Erosion Efficiency on Erosion Rate. The erosion efficiency $(\eta)$ is an important parameter [27] which is used for identifying the brittle and ductile erosion response of various materials to solid particle erosion. It is obtained by using the following equation:

$$
\eta=\frac{2 E H}{\rho v^{2}},
$$

where " $E$ " is erosion rate $(\mathrm{kg} / \mathrm{kg})$, " $H$ " is hardness of eroding material $(\mathrm{Pa}), " \rho$ " is density of eroding material $\left(\mathrm{kg} / \mathrm{m}^{3}\right)$, and " $v$ " is velocity of impact $(\mathrm{m} / \mathrm{s})$. The erosion efficiency can be used to identify the erosion mechanism of various materials. For example, ideal microploughing involving just the displacement of material from the crater without any fracture (and hence no erosion) will have zero erosion efficiency. Alternatively, in the case of ideal microcutting, $\eta$ will be unity. In case erosion occurs by the formation of a lip and its subsequent fracture, erosion efficiency will be in the range of $0-1$. In contrast, as happens with brittle material, if the erosion takes place by spalling and removal of large chunks of material by interlinking of lateral or radial cracks, then the erosion efficiency is expected to be even greater than $100 \%$.

The values of the erosion efficiencies of PVA and its composites calculated using (3) for different impact velocities have been shown in Figure 6. Since the steady-state erosion rate $(E)$ of PVA and its composites increases with increase in impact velocity " $v$," which is proportional to $v^{2}$, hence, erosion efficiency is expected to increase with increasing " $v$." The calculated results have been manifested in graphs (Figure 6) for different weight percentages of DPL fiber reinforced PVA composites. It has been observed from the graph that the erosion efficiencies vary from 4.316 to $16.289 \%$ for different impact velocities studied. Thus, it can be concluded that erosion takes place by microploughing and microcutting. As fiber content increases, erosion efficiency increases. 

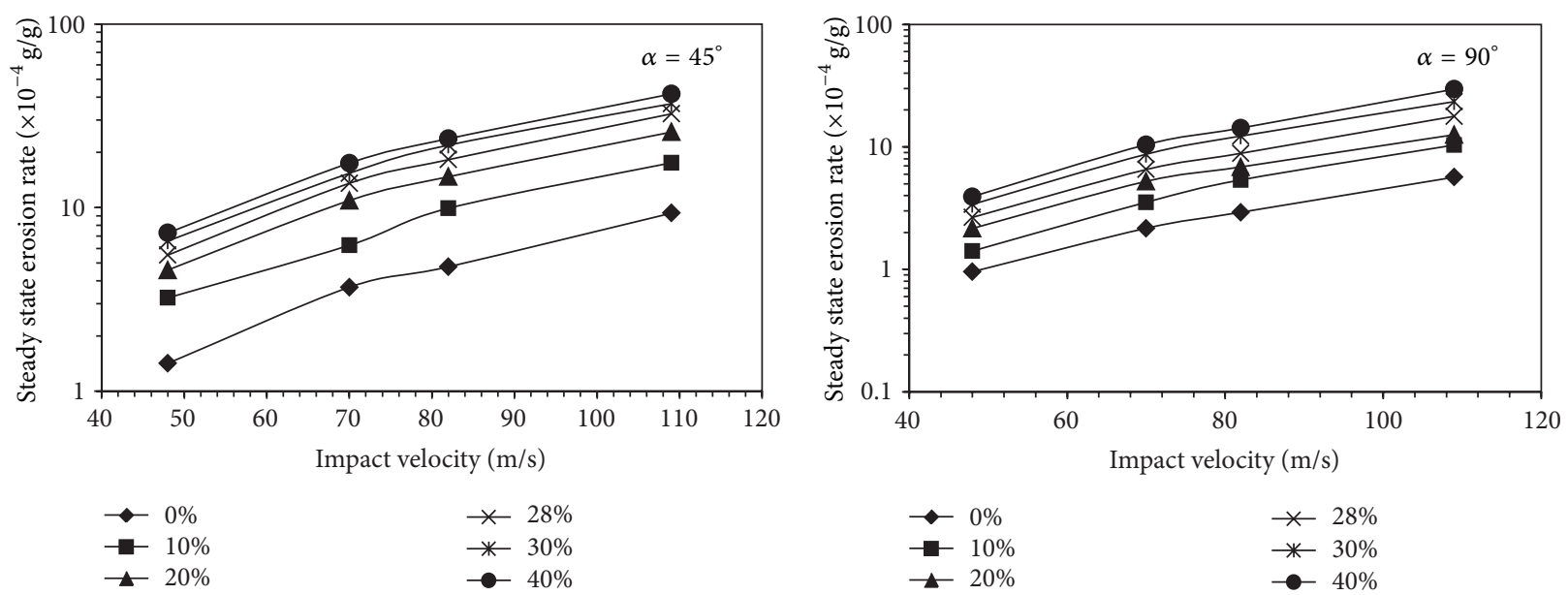

FIGURE 5: Variation of steady-state erosion rate of PVA/DPL composite as a function of impact velocity (45-109 m/s).

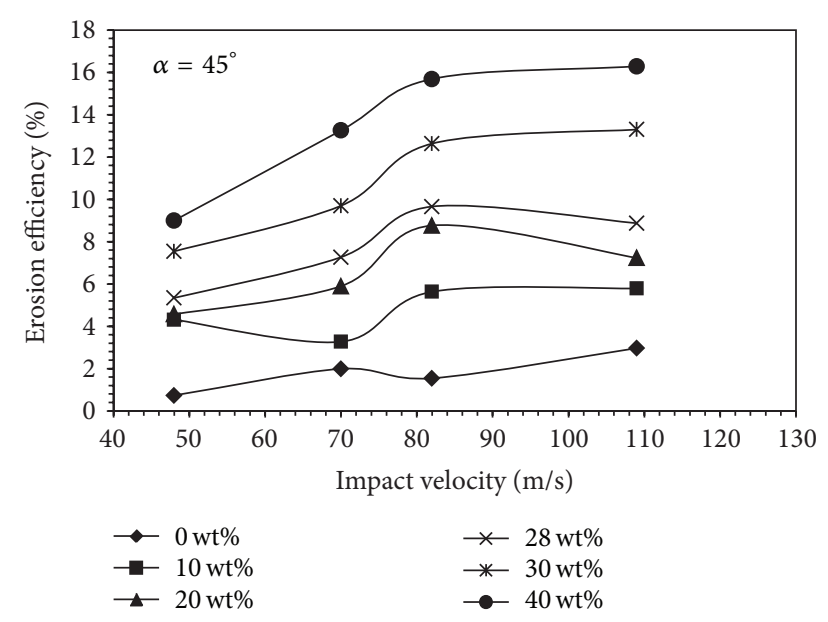

FIGURE 6: Erosion efficiency as a function of impact velocity for PVA/DPL composites.

A $40 \mathrm{wt} \%$ DPL fiber reinforcement to neat PVA matrix leads to a significant increase in erosion efficiency thereby decreasing erosion resistance.

3.5. Surfaces Morphology of Eroded Surface. Surface morphology of eroded surface is usually studied in order to ascertain the wear mechanism taking place in solid particle erosion. As observed in earlier work [22], 28\% was the optimum weight percentage of DPL fiber in PVA/DPL composites to get the maximum mechanical properties. Therefore, scanning electron microscopy (SEM) study was conducted on 28 wt $\%$ PVA/DPL composites for $30^{\circ}, 45^{\circ}, 60^{\circ}$, and $90^{\circ}$ impingement angles at constant impact velocity of $70 \mathrm{~m} / \mathrm{s}$ (Figure 7).

Figure 7(a) shows the SEM micrograph of the composite at low impact angle $\left(30^{\circ}\right)$. As depicted in the figure, there is formation of craters due to penetration of dry silica sand particles onto the surface thereby causing material loss from the matrix regime. The material removal in the composite is mostly dominated by microploughing, microcutting, and plastic deformation. The plastically deformed material subsequently removed from the surface by microcutting leads to maximum erosion at $45^{\circ}$ impingement angle. The matrix covering the fibers seems to be chipped off and the fibers are normally exposed to erosive environment. The formation of microcracks and embedment of fragments of sand particles are also evident from the micrograph (Figure 7(b)).

\section{Conclusions}

Experiments were conducted to study the solid particle erosion of date palm leaf fiber reinforced polyvinyl alcohol (PVA/DPL) composites with silica sand as erodent. Based on the studies, the following conclusions are drawn.

(1) The experimental parameters such as cumulative weight of impinging particles, impingement angle, and impact velocity have strong effect on erosive wear performance of PVA and its composites.

(2) From the variation of incremental erosion rate with cumulative mass of impinging particles, it is observed that initial mass gain and incubation period are not found for PVA and its composites. However, acceleration, deceleration, and stabilization are observed under various experimental conditions.

(3) It is observed that the impact velocity $(v)$ has a tremendous effect on the steady-state erosion rate $(E)$ of PVA and its composites and displays a power law behavior with velocity $(v): E=K v^{n}$, where " $n$ " varies from 2.0 to 2.88 .

(4) The influence of impingement angle on erosive wear of PVA/DPL composites under consideration exhibits semiductile behavior with maximum erosion at $45^{\circ}$ impingement angle for all weight percentages of DPL fibers at different impact velocities studied. Further, it is observed that the erosion efficiency of PVA and its composites varies from 0.735 to $16.289 \%$. This means 


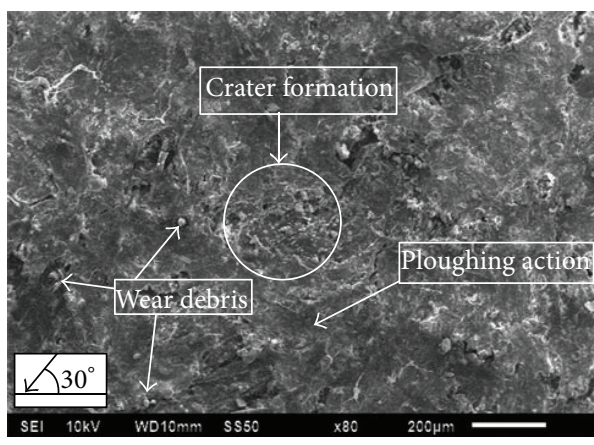

(a)

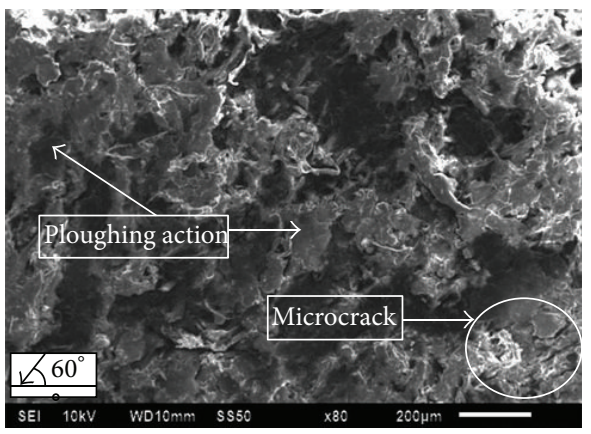

(c)

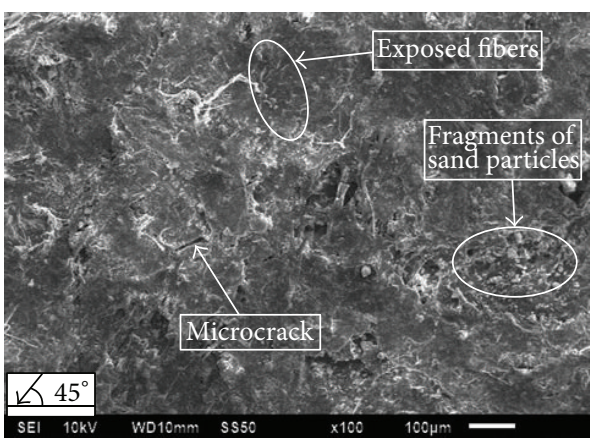

(b)

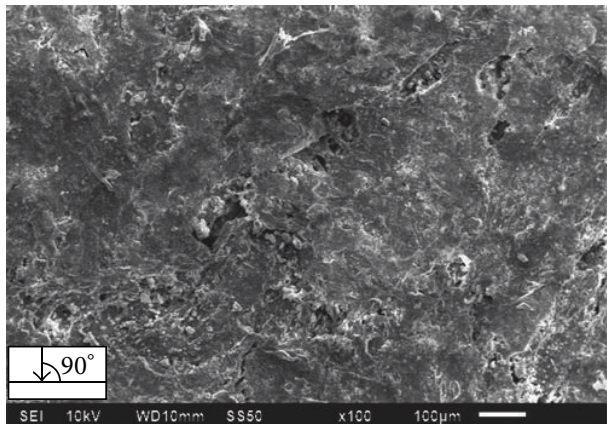

(d)

FIGURE 7: SEM micrographs of the eroded surfaces of $28 \mathrm{wt} \%$ of PVA/DPL composites.

that the erosion takes place by microploughing and microcutting.

(5) SEM studies of worn surfaces support the involved mechanisms and indicated microploughing, microcutting, plastic deformation, matrix removal, and exposure of fibers.

(6) It is concluded that if DPL fiber reinforced PVA composites have to be used in erosive situations, it is preferable to use $28 \mathrm{wt} \%$ of DPL fiber in PVA matrix which can also give optimum mechanical properties.

\section{Conflict of Interests}

With the proper authenticity from the coauthors, Jyoti R. Mohanty declares that there is no conflict of interests.

\section{References}

[1] Y. Li, Y.-W. Mai, and L. Ye, "Sisal fibre and its composites: a review of recent developments," Composites Science and Technology, vol. 60, no. 11, pp. 2037-2055, 2000.

[2] A. K. Bledzki and J. Gassan, "Composites reinforced with cellulose based fibres," Progress in Polymer Science, vol. 24, no. 2, pp. 221-274, 1999.

[3] R. Kozłowski and M. Władyka-Przybylak, "Flammability and fire resistance of composites reinforced by natural fibers," Polymers for Advanced Technologies, vol. 19, no. 6, pp. 446-453, 2008.
[4] J. J. Rajesh, J. Bijwe, U. S. Tewari, and B. Venkataraman, "Erosive wear behavior of various polyamides," Wear, vol. 249, no. 8, pp. 702-714, 2001.

[5] A. P. Harsha and A. A. Thakre, "Investigation on solid particle erosion behaviour of polyetherimide and its composites," Wear, vol. 262, no. 7-8, pp. 807-818, 2007.

[6] U. S. Tewari, A. P. Harsha, A. M. Häger, and K. Friedrich, "Solid particle erosion of carbon fibre- and glass fibre-epoxy composites," Composites Science and Technology, vol. 63, no. 34, pp. 549-557, 2003.

[7] J. Bijwe, J. Indumathi, J. J. Rajesh, and M. Fahim, "Friction and wear behavior of polyetherimide composites in various wear modes," Wear, vol. 249, no. 8, pp. 715-726, 2001.

[8] J. Bijwe, J. Indumathi, and A. K. Ghosh, "On the abrasive wear behaviour of fabric-reinforced polyetherimide composites," Wear, vol. 253, no. 7-8, pp. 768-777, 2002.

[9] B. C. Patel, S. K. Acharya, and D. Mishra, "Effect of stacking sequence on the erosive wear behavior of jute and jute-glass fabric reinforced epoxy composite," International Journal of Engineering, Science and Technology, vol. 3, no. 1, pp. 213-219, 2011.

[10] S. Biswas and A. Satapathy, "A comparative study on erosion characteristics of red mud filled bamboo-epoxy and glassepoxy composites," Materials \& Design, vol. 31, no. 4, pp. 17521767, 2010.

[11] A. Satapathy, A. Patnaik, and M. K. Pradhan, "A study on processing, characterization and erosion behavior of fish (Labeorohita) scale filled epoxy matrix composites," Materials \& Design, vol. 30, no. 7, pp. 2359-2371, 2009. 
[12] N. Miyazaki and N. Takeda, "Solid particle erosion of fiber reinforced plastics," Journal of Composite Materials, vol. 27, no. 1, pp. 21-31, 1993.

[13] N. Miyazaki and T. Hamao, "Solid particle erosion of thermoplastic resins reinforced by short fibers," Journal of Composite Materials, vol. 28, no. 9, pp. 871-883, 1994.

[14] A. P. Harsha, U. S. Tewari, and B. Venkatraman, "Solid particle erosion behaviour of various polyaryletherketone composites," Wear, vol. 254, no. 7-8, pp. 693-712, 2003.

[15] K. V. Pool, C. K. H. Dharan, and I. Finnie, "Erosive wear of composite materials," Wear, vol. 107, no. 1, pp. 1-12, 1986.

[16] F. A. Al-Sulaiman, "Date palm fibre reinforced composite as a new insulating material," International Journal of Energy Research, vol. 27, no. 14, pp. 1293-1297, 2003.

[17] A. Sbiai, A. Maazouz, E. Fleury, H. Sautereau, and H. Kaddami, "Short date palm tree fibers/polyepoxy composites prepared using RTM process: effect of tempo mediated oxidation of the fibers," BioResources, vol. 5, no. 2, pp. 672-689, 2010.

[18] S. Mahdavi, H. Kermanian, and A. Varshoei, "Comparison of mechanical properties of date palm fiber- polyethylene composite," BioResources, vol. 5, no. 4, pp. 2391-2403, 2010.

[19] K. M. M. Rao and K. M. Rao, "Extraction and tensile properties of natural fibers: vakka, date and bamboo," Composite Structures, vol. 77, no. 3, pp. 288-295, 2007.

[20] A. Alawar, A. M. Hamed, and K. Al-Kaabi, "Characterization of treated date palm tree fiber as composite reinforcement," Composites B, vol. 40, no. 7, pp. 601-606, 2009.

[21] F. Al-Sulaiman, "Mechanical properties of date palm leaves," Journal of Reinforced Plastics \& Composites, vol. 19, no. 17, pp. 1379-1388, 2000.

[22] J. R. Mohanty, S. N. Das, H. C. Das, and S. K. Swain, "Effective mechanical properties of polyvinylalcohol biocomposites with reinforcement of date palm leaf fibers," Polymer Composite, vol. 34, no. 6, pp. 959-966, 2013.

[23] A. W. Ruff and L. K. Ives, "Measurement of solid particle velocity in erosive wear," Wear, vol. 35, no. 1, pp. 195-199, 1975.

[24] A. P. Harsha and A. A. Thakre, "Investigation on solid particle erosion behaviour of polyetherimide and its composites," Wear, vol. 262, no. 7-8, pp. 807-818, 2007.

[25] T. H. Tsiang, "Sand erosion of fibre composites: testing and evaluation," in Test Methods and Design Allowables for Fibrous Composites, C. C. Chamis, Ed., vol. 2 of STP 1003, pp. 46-55, ASTM International, Philadelphia, Pa, USA, 1989.

[26] G. P. Tilly and W. Sage, "The interaction of particle and material behaviour in erosion processes," Wear, vol. 16, no. 6, pp. 447465, 1970.

[27] G. Sundararajan, M. Roy, and B. Venkataraman, "Erosion efficiency-a new parameter to characterize the dominant erosion micromechanism," Wear, vol. 140, no. 2, pp. 369-381, 1990. 

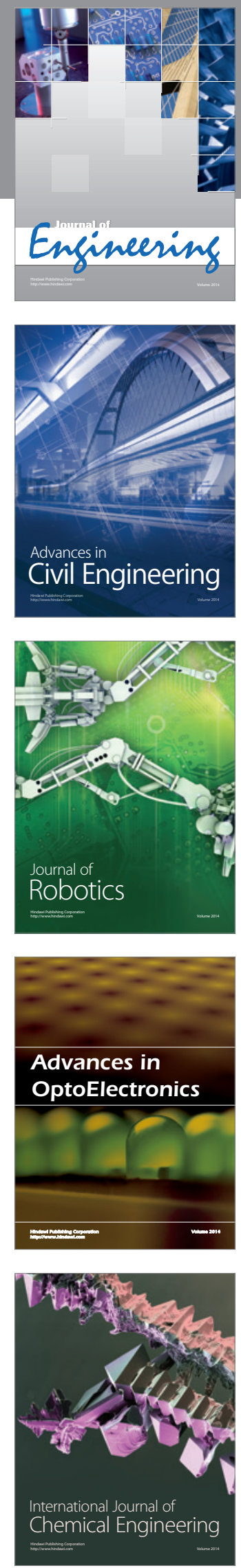

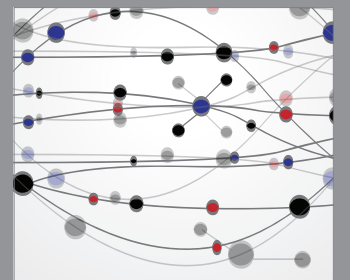

The Scientific World Journal
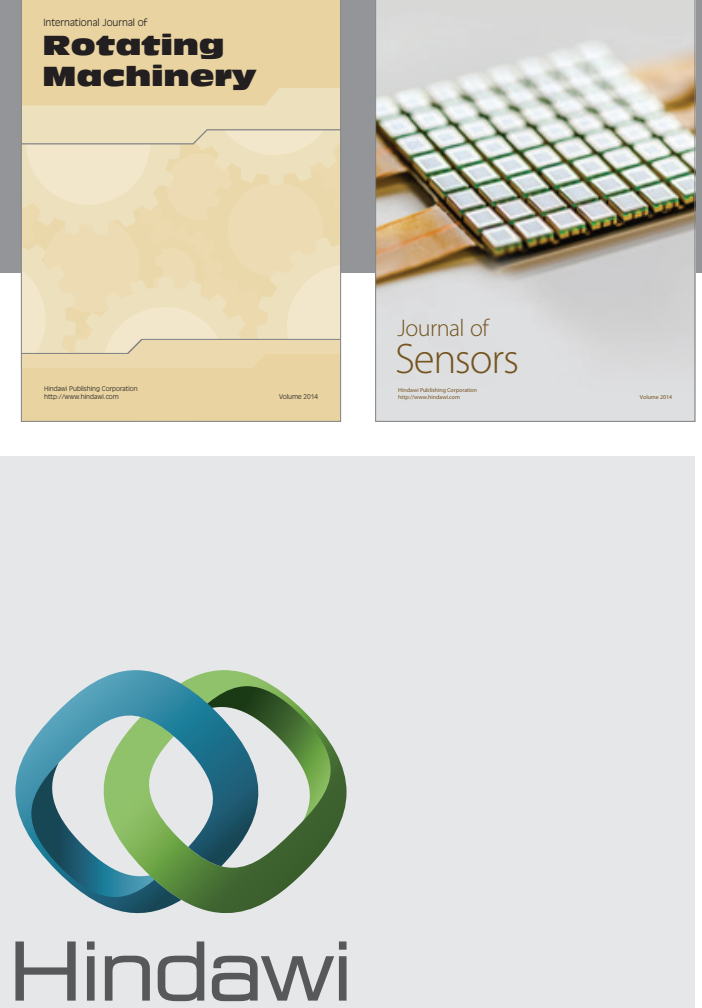

Submit your manuscripts at http://www.hindawi.com
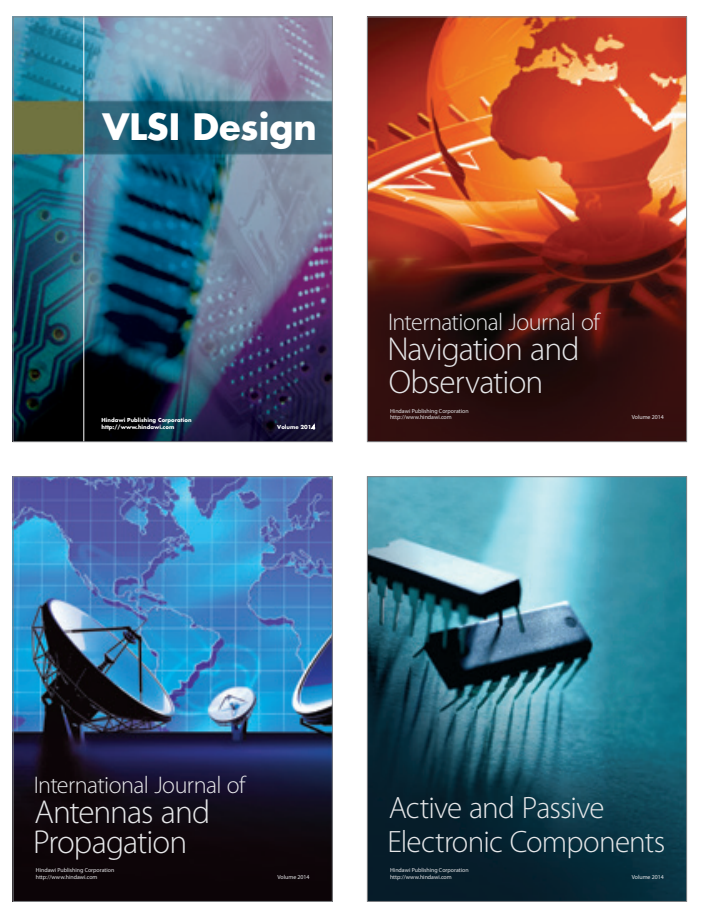
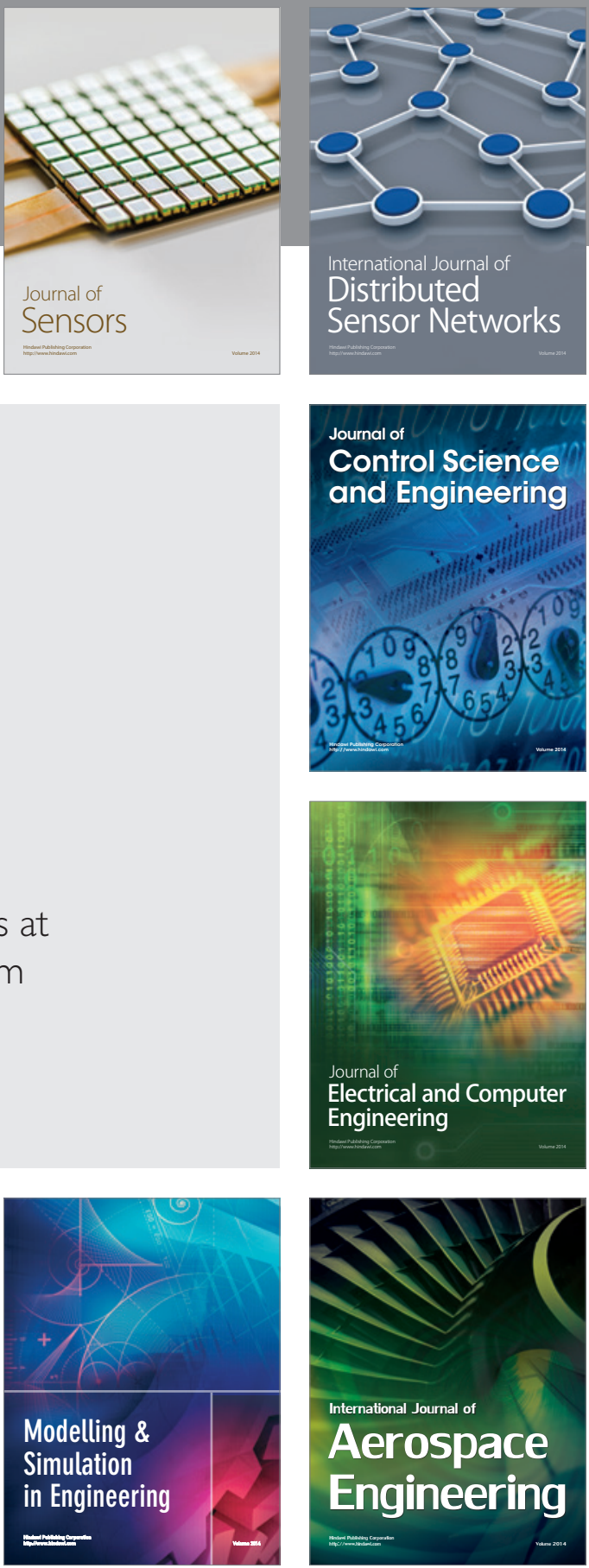

Journal of

Control Science

and Engineering
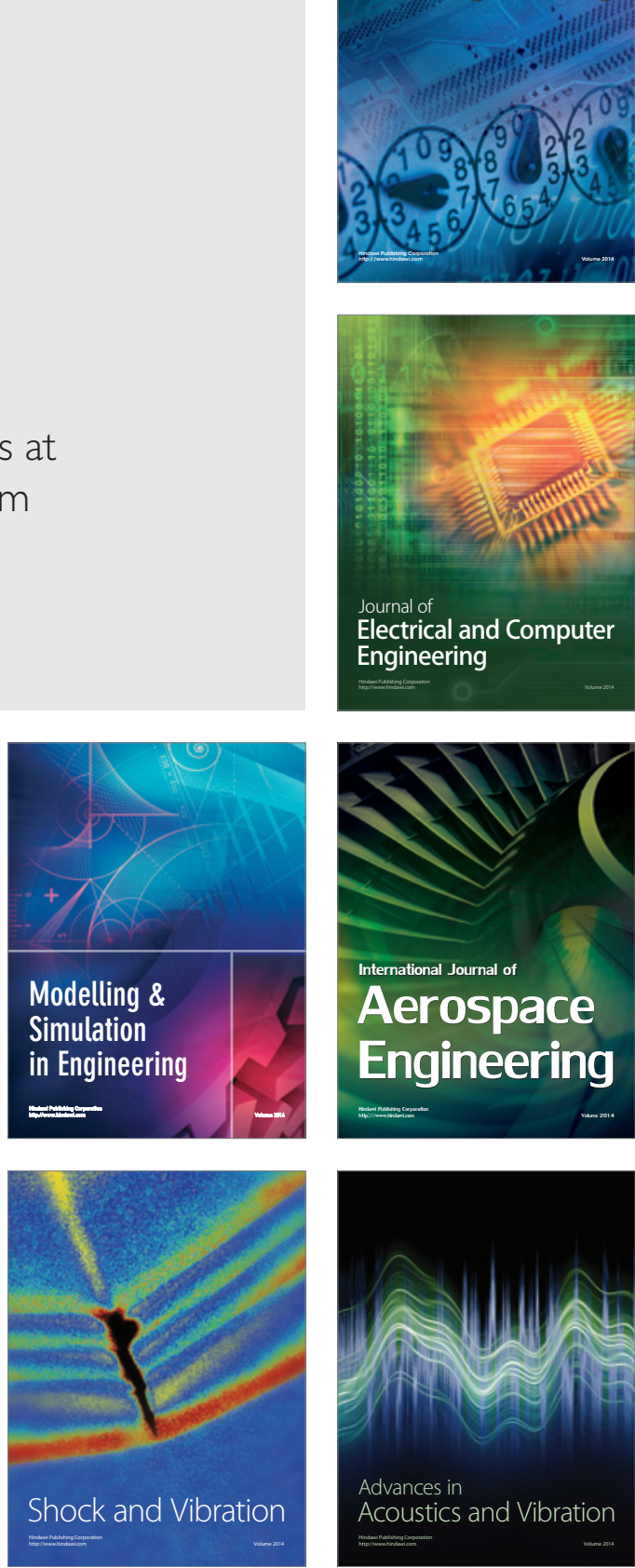